\title{
Development and Performance Evaluation of a Solar Tunnel Date Dryer in Oman
}

\author{
Mohammad Ali Basunia ${ }^{\star \star}$, Hamid Hamad Al-Handali ${ }^{1}$, \\ Mohammed Issa Al-Balushi', Mohammad Shafiur Rahman², \\ and Osman Mahgoub ${ }^{3}$
}

'Department of Soils, Water and Agricultural Engineering, ${ }^{2}$ Department of Food Science and Nutrition, ${ }^{3}$ Department of Animal and Veterinary Sciences, College of Agricultural and Marine Sciences, Sultan Qaboos University, P.O. Box 34, Al-Khod123, Sultanate of Oman
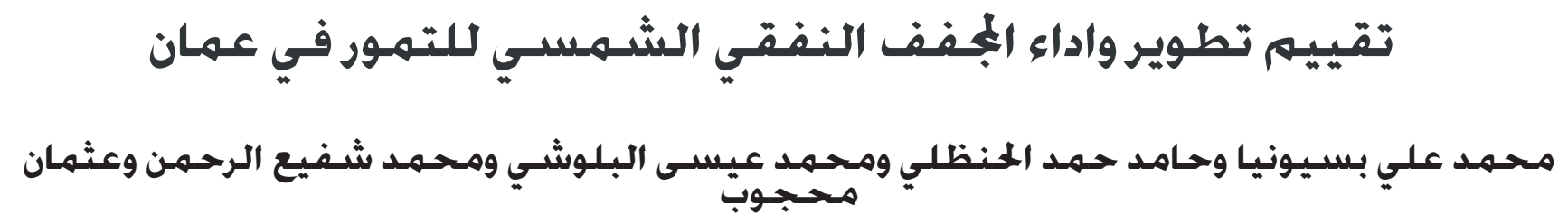

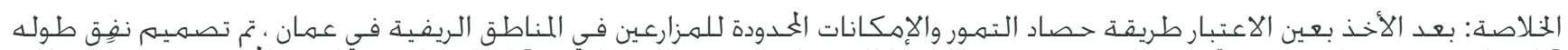

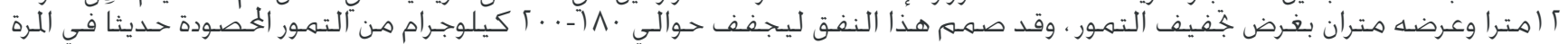

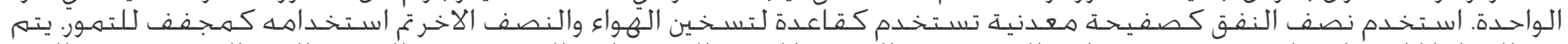

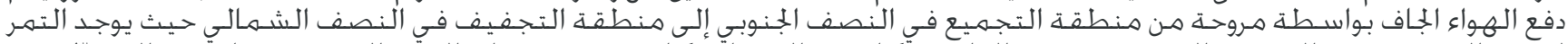

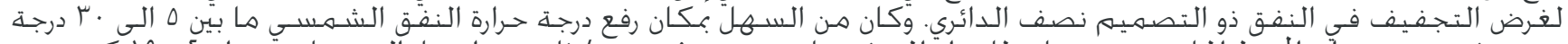

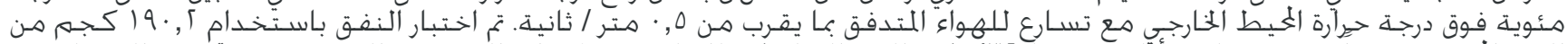

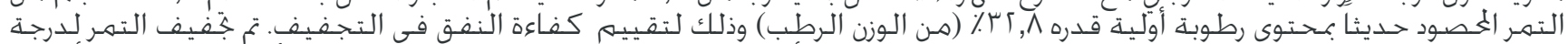

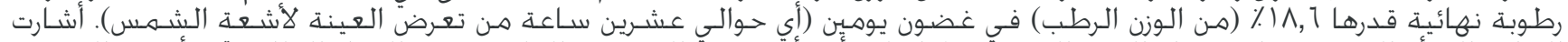

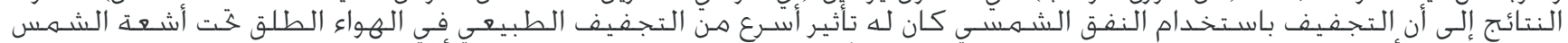

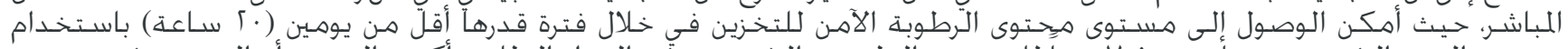

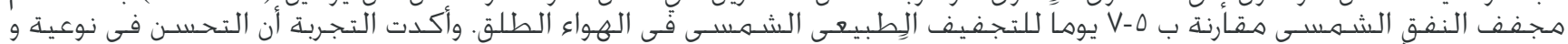

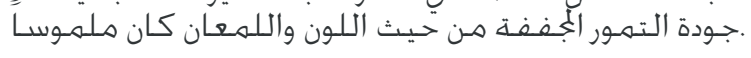

$$
\text { كلمات مفتاحية: التجفيف ، التمور ، نفق جّفيف شـمسي ، هستوى الرطوبة }
$$

ABSTRACT: Taking into consideration the date harvesting and landholding capacities of the marginalized rural farmers in Oman, a 12 meter long and 2 meter wide tunnel was designed and constructed to dry about 180-200 kg of freshly harvested dates per batch. Half of the tunnel base was used as a flat plate air heating solar collector and the other half as a dryer. The drying air was forced from the collector region (South side) to the drying region (North side) of the half circled tunnel where the product is to be dried. The drying temperature could be easily raised by some $5-30{ }^{\circ} \mathrm{C}$ above the ambient temperature inside the tunnel at an air velocity of approximately $0.5 \mathrm{~m} / \mathrm{sec}$. The test was conducted with $190.2 \mathrm{~kg}$ freshly harvested dates with initial moisture content of $32.8 \%$ (wet-basis) to analyze the performance of the dryer. The dates were dried to a final average moisture content of $18.6 \%$ (wet-basis) within two days ( 20 hours). The results indicated that the drying was faster in a solar tunnel dryer than the natural open air sun drying. It was possible to reach the moisture content level for safe storage within less than two days (20 hrs) with a solar tunnel dryer and 5-7 days in open air natural sun drying. The improvement in the quality of dates in terms of color and brightness was distinctly recognized.

Keywords: Drying, dates, solar tunnel dryer, moisture content.

\section{Introduction}

Drying is very important because it is the cheapest, easiest and most common method of preserving and storing of perishable agricultural products. There are various methods and techniques to dry grain and other agricultural products. Each method has its own advantages and limitations. Dried products are becoming a common alternative to freshly harvested products due to many advantages (Lutz et al., 1987).

Annual production of dates in Oman is estimated about 200,000 tones (Ampratwum, 2003). Most of the dates are still dried by the traditional method of open air natural sun drying. This method of drying normally takes 14 to 21 days in Oman (Ampratwum, 2003). The traditional open air natural sun drying methods often yield poor quality dried products. In most cases the drying yard is not properly fenced. The product is not protected against dust, rain and wind, or even against insects, birds, rodents and domestic animals during the drying process. Thus, the final product is contaminated with microorganisms and infection with disease-causing germs. The dates dried in this way have a short shelf-life and may not be free from contamination. The solar drying 


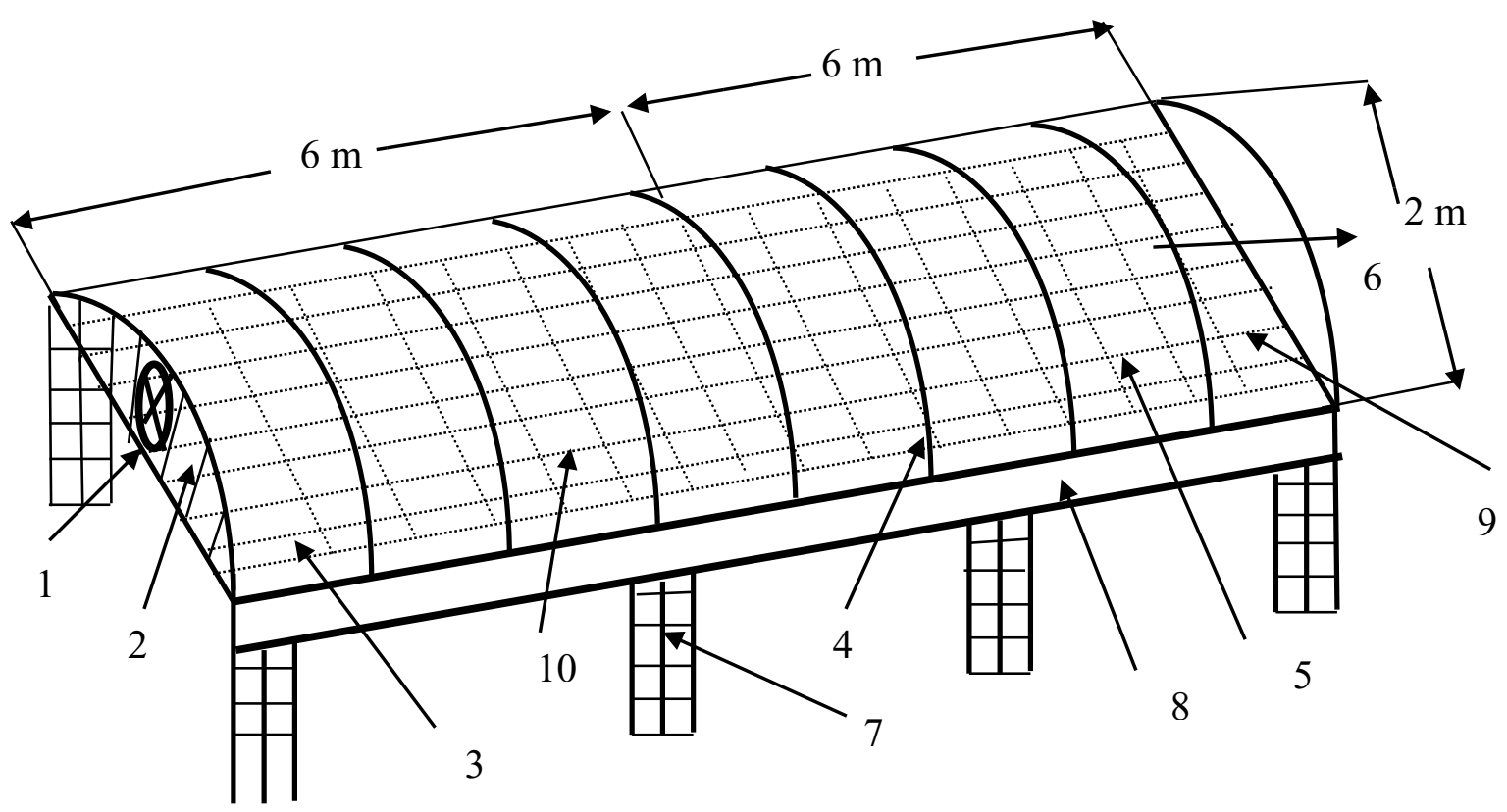

Figure 1. A rough sketch of a solar tunnel dryer used in this study without plastic cover and part of wooden base of the tunnel (1- Air inlet to the collector, fan, 2- South side wooden cover, 3-Collector part (12 $\left.\mathrm{m}^{2}\right)$, 4- Light weight aluminum frame, 5- Dryer part $\left(12 \mathrm{~m}^{2}\right)$ 6- Air outlet from the dryer, 7- Concrete block sub-structures, 8- Wooden frame to support bends and base of the tunnel; 9- Metallic wire mesh net over wooden base in the dryer part, 10- Absorber plate (black painted metallic sheet over wooden base, not visible in figure, $12 \mathrm{~m}^{2}$ )

facilities combine the advantages of traditional and industrial methods, namely low investment costs and high product quality.

Ampratwum (2003) reported the construction procedures and test results of a natural convection solar date dryer at Sultan Qaboos University, but due to low drying rates and capacity, it had not gained popularity in Oman.

A successful new solar tunnel drier was designed and developed at the University of Hohenheim, Germany, to meet the drying requirements of small farmer cooperatives (Lutz et al., 1987; Esper et al., 1994, 1996). This dryer is classified as a solar dryer that has been successfully tested under field conditions in about 30 countries under different climatic conditions in drying various agricultural products (Schirmer et al., 1996; Mastekbayeva et al., 1998; Bala and Mondal, 2001; Basunia and Abe 2001a, 2001b; EI-Sebaii et al., 2002; Bala et al., 2003). This new dryer design eliminated the dependence on grid electricity since the power consumption of the fan could be supplied by batteries or solar PV panels. Unfortunately, the solar tunnel dryer has not yet been tested here in Oman where solar energy is abundant and can be used for drying of dates and other agricultural products.

The original design of the dryer $(20 \times 2 \mathrm{~m})$, however, had a capacity that is suitable for use in a large farm. In order to adapt its design for small and medium scale rural farmers of Oman, a scaled down $(12 \times 2 \mathrm{~m})$ prototype of the tunnel dryer was designed and fabricated for the experiment at the Department of Soils, Water and Agricultural Engineering at Sultan Qaboos University, Oman.

\section{Materials and Methods}

The prototype solar tunnel dryer consists of a flat plate air heating solar collector and drying tunnel, fabricated as a single unit (Fig. 1). The tunnel is $2.0 \mathrm{~m}$ wide, with a collector and dryer length of $6.0 \mathrm{~m}$, respectively. The light-weight aluminum frames were used as the upper structure for the entire tunnel to support the transparent plastic cover. The tunnel was placed on concrete block substructures $700 \mathrm{~mm}$ above the ground surface. The plywood planks $(0.9 \times 2.0 \mathrm{~m})$ of $4 \mathrm{~mm}$ thickness were used as the bed both for the dryer and collector parts of the tunnel to make the base of the tunnel almost air-tight. Over the wooden base, black painted metallic sheets $(0.9 \times$ $2.0 \mathrm{~m}$ ) of $0.25 \mathrm{~mm}$ thickness were used as the absorber plate in the collector section of the tunnel. The steel wire mesh net was spread over the wooden dryer base to dry the desired product. A $0.2 \mathrm{~mm}$ thick UV stabilized colorless polyethylene sheet was used as the transparent cover over the entire tunnel (collector and dryer area). The entire tunnel became almost air-tight except the inlet opening (south side) for fixing a fan and the exit side (north side) for the moist air. The light weight $(30 \times 1 \mathrm{~mm})$ aluminum flat bars were cut into pieces, each having a length 3140 $\mathrm{mm}$ and were bent to half-circles before being fixed onto the wooden base of the tunnel. 
A solar-powered fan of 40 watt capacity was installed at the holes made on the wooden cover plate, $150 \mathrm{~mm}$ above the metallic absorber sheet at the air input side of the tunnel. Thus, the drying air was forced from the collector region to the dryer region where the product is to be dried. The fan has an air handling capacity of $7.3 \mathrm{~m}^{3} / \mathrm{min}$ against a maximum static pressure of $157 \mathrm{~Pa}\left(16 \mathrm{mmH}_{2} \mathrm{O}\right)$. The design of the dryer was based on the consideration that the temperature of air heated in the collector and forced to pass through the dryer section would not exceed $60^{\circ} \mathrm{C}$. This is based on the principle of low temperature drying of agricultural crops. The maximum permissible temperature for fruits and vegetable drying is about $60^{\circ} \mathrm{C}$ to maintain the optimum quality of the dried product; the temperature at the outlet of the collector and at the entrance of the dryer should not exceed this limit.

Prior to the operation of the dryer, thermocouples were installed to record the temperatures at different locations within the tunnel. Nine thermocouples were connected within the tunnel, three at each of the mid-points of the collector, the dryer and of the whole tunnel. The copper constantan thermocouples were used to measure the temperature by fixing them inside the tunnel. The drybulb temperatures in the collector part of the tunnel were measured at $50 \mathrm{~mm}$ above the surface of the black metallic sheet, $50 \mathrm{~mm}$ below the inner surface of the transparent plastic cover and at the mid point $(500 \mathrm{~mm}$ above the absorber plate) of these two surfaces along the lengthwise center of the tunnel. Similarly, the thermocouples were connected at the mid-points of the dryer part and the tunnel, respectively, to measure the temperature profiles both in the vertical and horizontal directions of the entire tunnel. Also, two thermocouples were used to measure the dry- and wet-bulb temperatures of the ambient air. Thus, in total, eleven thermocouples were used to measure the temperatures at different locations. So the dry-bulb temperatures in the collector and dryer represented the average of three readings, respectively. The temperature inside the tunnel represented the average of nine readings. The thermocouples used for measuring the temperatures had an accuracy of $\pm 0.5^{\circ} \mathrm{C}$. An anemometer was used to measure the velocity at the exit of the dryer. A pyranometer of Moll - Goregynstic type was used to measure the solar radiation incident on a horizontal surface. The sensitivity of pyranometer was $10.5 \mathrm{mV} /\left(\mathrm{cal} . \mathrm{cm}^{2} . \mathrm{min}\right)$. The thermocouple probes, anemometer and pyranometer were connected through an interface of an AD (analog to digital) converter then to a personal computer for data collection. The temperatures, air velocity and solar radiation data were recorded simultaneously at intervals of 30 minutes. Experiments were conducted to evaluate the performance of the dryer at no-load and full-load conditions.

The moisture content of whole dates was determined by using oven drying method. The sample of whole dates was kept at $100{ }^{\circ} \mathrm{C}$ for 20 hours (AOAC, 1984). Date samples were collected at intervals of one hour from the tunnel on the first day and then at two hour intervals on the second day of drying. Also, a test sample of about $1 \mathrm{~kg}$ was conducted in the open air (control) under natural convection and simultaneously in the solar tunnel dryer to compare their drying rates.

The drying efficiency of the dryer was calculated from the measured solar energy input to the collector and the electrical energy supplied by the single fan during operations. The solar radiation incident directly on the drying portion of the tunnel was not considered for calculation of the drying efficiency as this energy had little effect on drying. Most of the energy directly input from the solar radiation on the dryer portion passed through the exit because of relatively higher air velocity and absence of open space in the dryer base.

The following parameters were considered for estimating the drying efficiency of the experimental solar tunnel dryer: (a) measured average total (diffuse and beam) solar irradiation on a horizontal surface to calculate solar irradiance on the collector surface, (b) geometric factor and efficiency of the collector at the test site, (c) total electrical energy input to the fan during operation from photovoltaic solar cells, and (d) initial and final mass of the dates and thus the amount of water removed from the dates in a given period of time.

The following equation was developed to calculate the drying efficiency of the dryer:

$$
\eta_{d}=\frac{100\left(W_{r} \cdot L_{v}\right)}{\left(P_{e}+S_{t} \cdot A_{c} \cdot R_{b} \cdot \eta_{c} \cdot t\right)}
$$

where $\eta_{\dot{d}}$ is the drying efficiency in percent; $W_{r}$ is the mass of moisture removed from the product in $\mathrm{kg} ; L_{v}$ is the latent heat of vaporization of water in $\mathrm{MJ} / \mathrm{kg} ; P_{e}$ is the total electrical energy required to run the $\mathrm{AC}$ fan during operation in $\mathrm{MJ} ; S_{t}$ is the measured total solar irradiation on a horizontal surface in $\mathrm{MJ} /\left(\mathrm{hr}_{\mathrm{m}} \mathrm{m}^{2}\right) ; A_{c}$ is the area of the collector in $\mathrm{m}^{2} ; R_{b}$ is the geometric factor at the test site; and $\eta_{c}$ is the efficiency at the test site and $t$ is the total drying time per hour.

\section{Results and Discussion}

\section{No-load Tests (test without product)}

The dryer was placed in the open farmyard of the Agricultural Experimental Station (AES) of Sultan Qaboos University. The no-load tests with and without fan were conducted to know the temperature and air flow characteristics at different weather conditions and also, the temperature gradient both in the collector and dryer regions of the tunnel. Figure 2 shows the variations of ambient, collector and dryer temperatures with time of day. The drying air temperature could be easily raised by some $5-30{ }^{\circ} \mathrm{C}$ above the ambient temperature at an air flow rate of $0.5-0.6 \mathrm{~m} / \mathrm{sec}$. The difference between the drying air temperature and ambient temperature gradually increased from morning till mid-day $\left(0-30^{\circ} \mathrm{C}\right)$ 


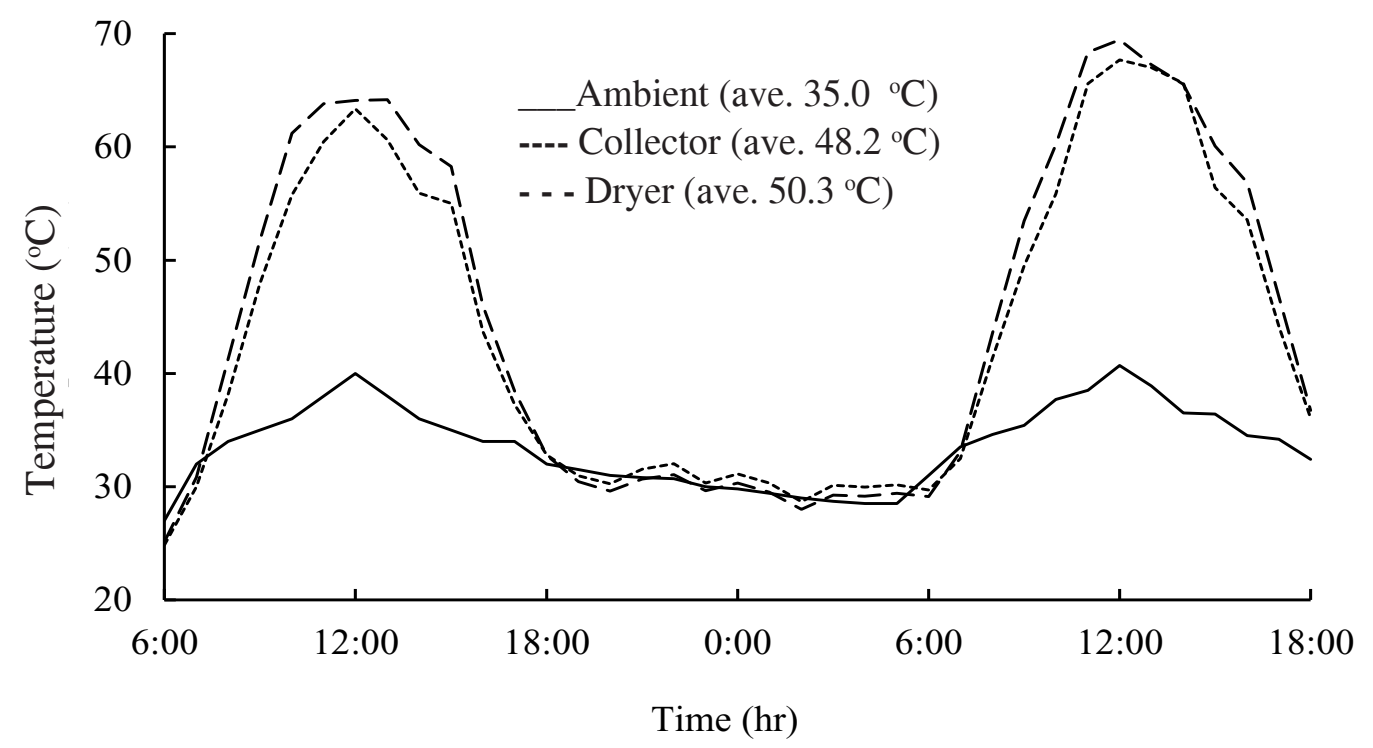

Figure 2. Variations of ambient, dryer and collector air temperatures with time of the day (August 8-9, 2008) under no load condition (with fan).

then gradually fell $\left(30-0^{\circ} \mathrm{C}\right)$ in the afternoon (Fig. 2). The highest temperature $69^{\circ} \mathrm{C}$ was observed at around 1:00 PM. However, the temperature could be maintained within 40$60^{\circ} \mathrm{C}$ by controlling the exit area of the tunnel, particularly from 11:30-15:30 hours when temperatures exceeded 60 ${ }^{\circ} \mathrm{C}$. This indicated that solar tunnel dryer can be easily used to dry dates. In no-load tests the maximum difference between the average temperatures of the dryer and collector parts was about $2{ }^{\circ} \mathrm{C}$. This indicated the uniformity of temperatures inside the entire tunnel.
There was almost no temperature gradient in the vertical direction of the whole tunnel, either in the dryer (Fig. 3) or the collector parts of the tunnel (Fig. 4). Figures 5-7 show the temperature profiles in the horizontal direction through the bottom, middle and top along the breadthwise center of the tunnel. There was almost no temperature gradient observed in the horizontal direction either in the dryer or collector parts of the tunnel due to proper mixing of the drying air by the fan (Figs. 5 to 7). Tests were conducted from 6:00 AM to 6:00 PM.

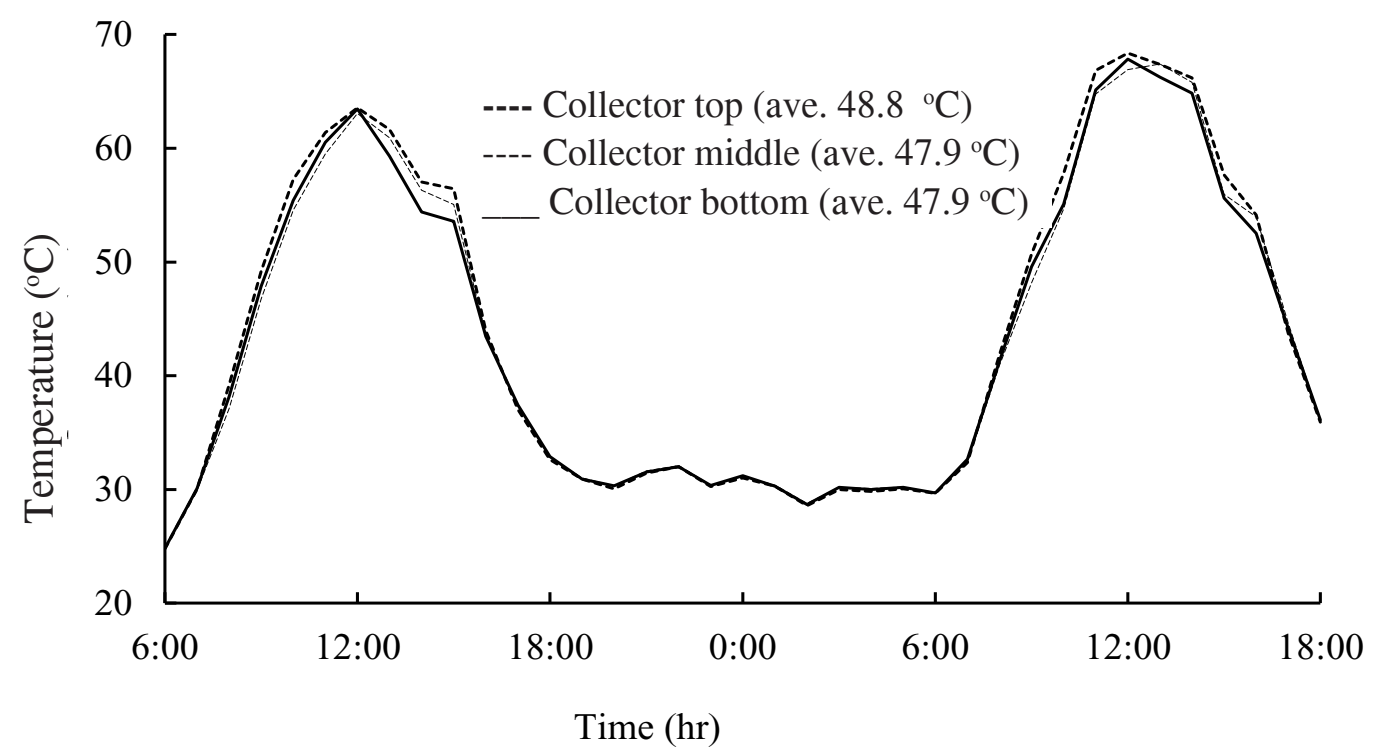

Figure 3. Variations of temperatures at the bottom, middle and top (vertical temperature profile) of the collector center along the length with time of the day (August 8-9, 2008) under no load condition (without product). 


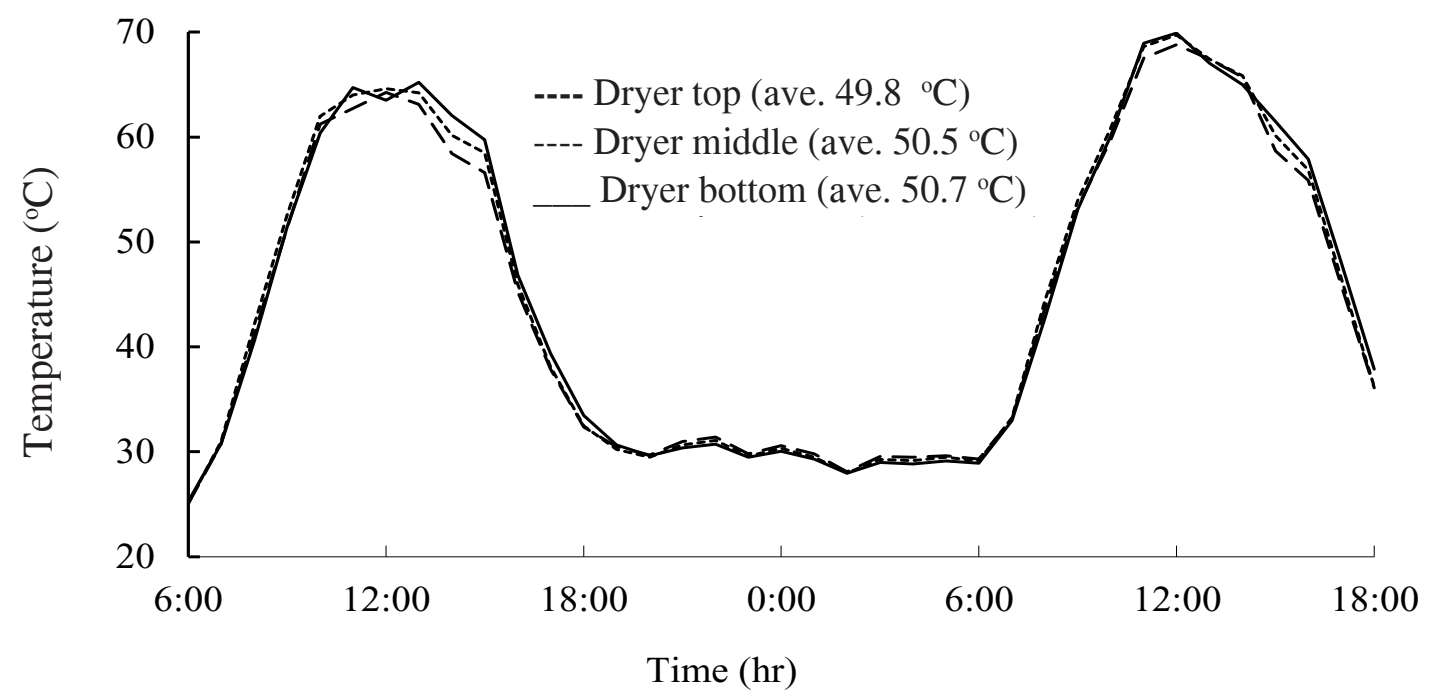

Figure 4. Variation of temperatures at the bottom, middle and top (vertical temperature profile) of the dryer part with time of the day (August 8-9, 2008) under no load condition (without product).

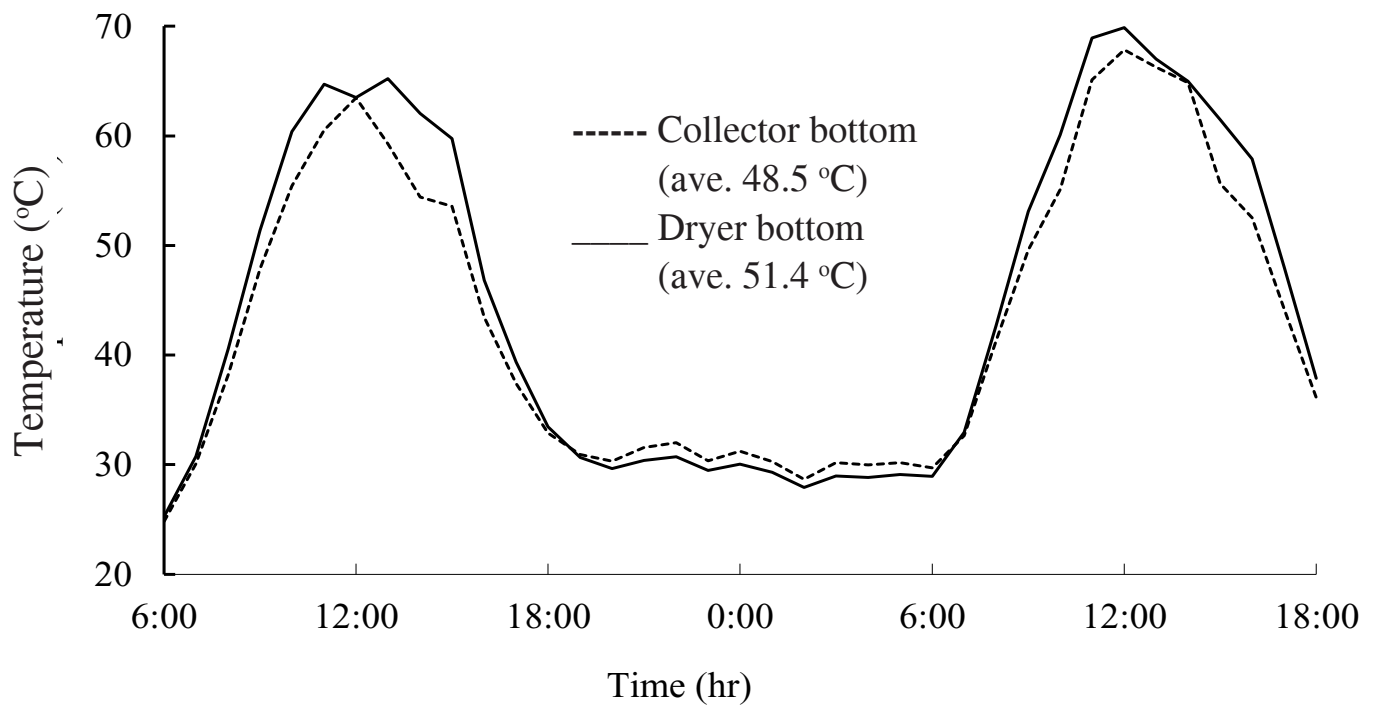

Figure 5. Variations of temperature in the horizontal direction of the tunnel through the bottom ( $5 \mathrm{~cm}$ from the base) along the center with time of the day (August 8-9, 2008) under no load condition (without product). 


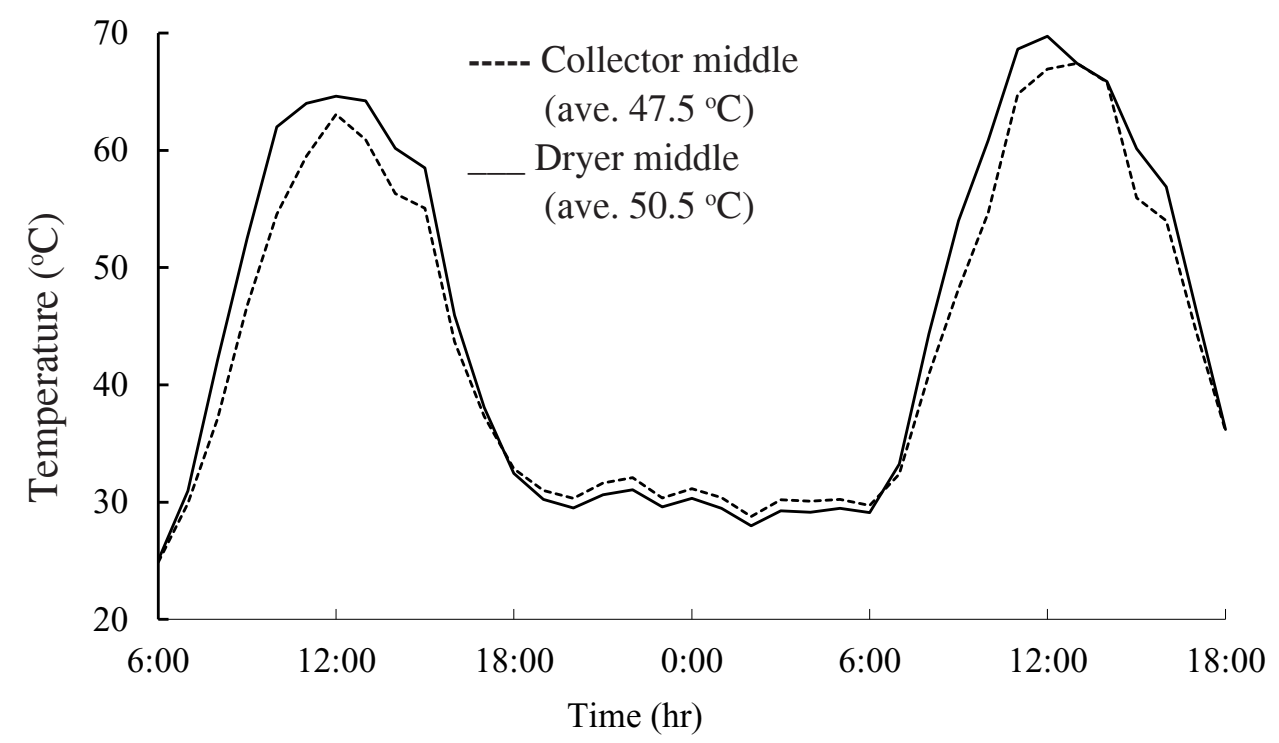

Figure 6. Variations of temperature in the horizontal direction of the tunnel through the middle $(50 \mathrm{~cm}$ from the base) along the center with time of the day (August 8-9, 2008) under no load condition (without product).

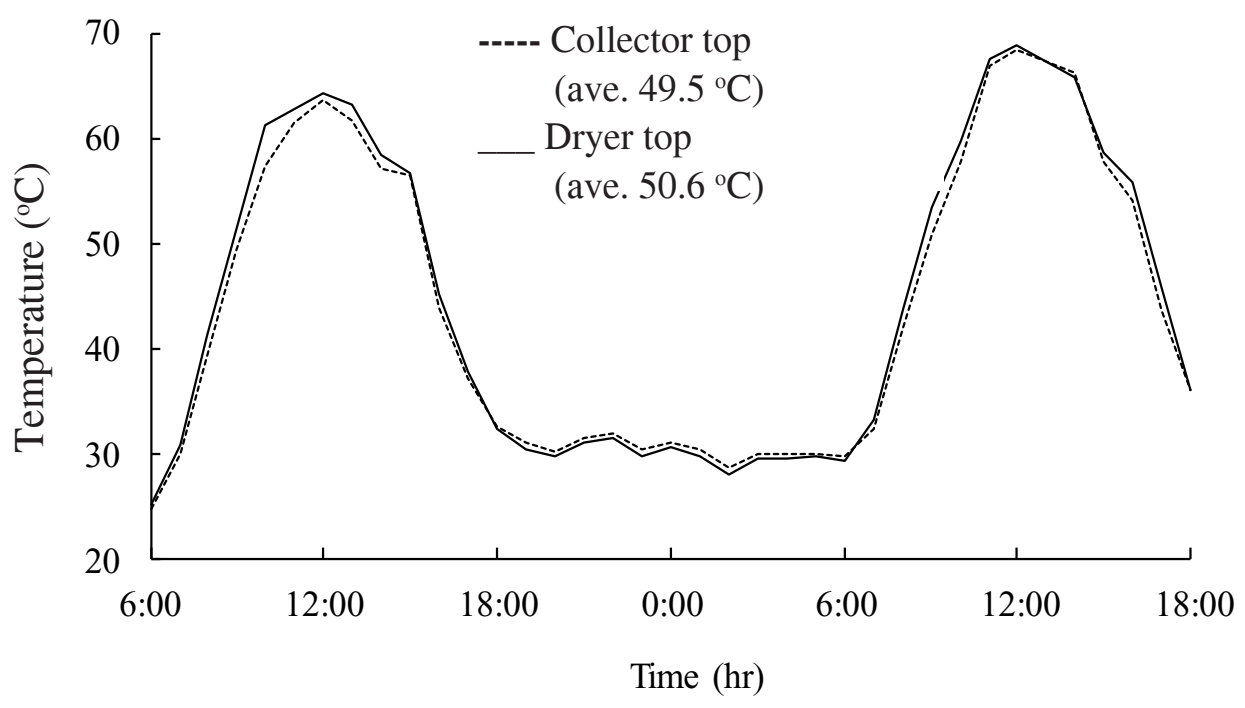

Figure 7. Variations of temperature in the horizontal direction of the tunnel through the top ( $90 \mathrm{~cm}$ from the base) along the center with time of the day (August 8-9, 2008) under no load condition (without product). 
A no-load test was also conducted without the fan being used. It was also observed that the highest temperature inside the tunnel rose to $75^{\circ} \mathrm{C}$ when the fan was not in operation (Figs. 8 and 9). The difference between the average temperatures inside the tunnel with and without fan was about $10^{\circ} \mathrm{C}$. This indicated the operation of the dryer without fan use would cause overdrying of the product particularly during 11:30 AM-
3:30 PM. Mercer (2008) mentioned that to avoid damage, temperatures below $60^{\circ} \mathrm{C}$ are quite appropriate for many food-drying applications. Figure 10 shows the variations of measured total (beam and diffuse) solar radiation on the horizontal surface with time of the day. It clearly indicated that an average $500 \mathrm{w} / \mathrm{m}^{2}$ solar energy was incident on the horizontal surface which can be easily utilized in drying dates.

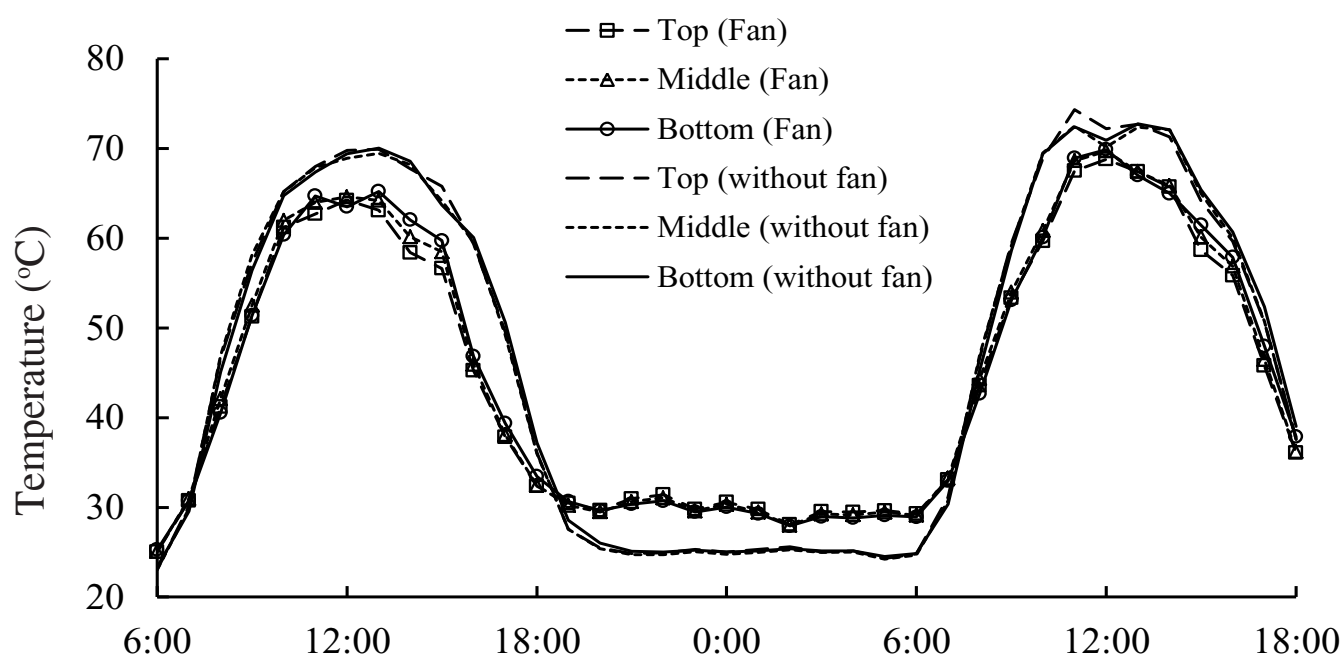

Time (hr)

Figure 8. Variations of temperatures in dryer part of the tunnel with and without fan under no-load conditions with time of the day (August 8-11, 2008).

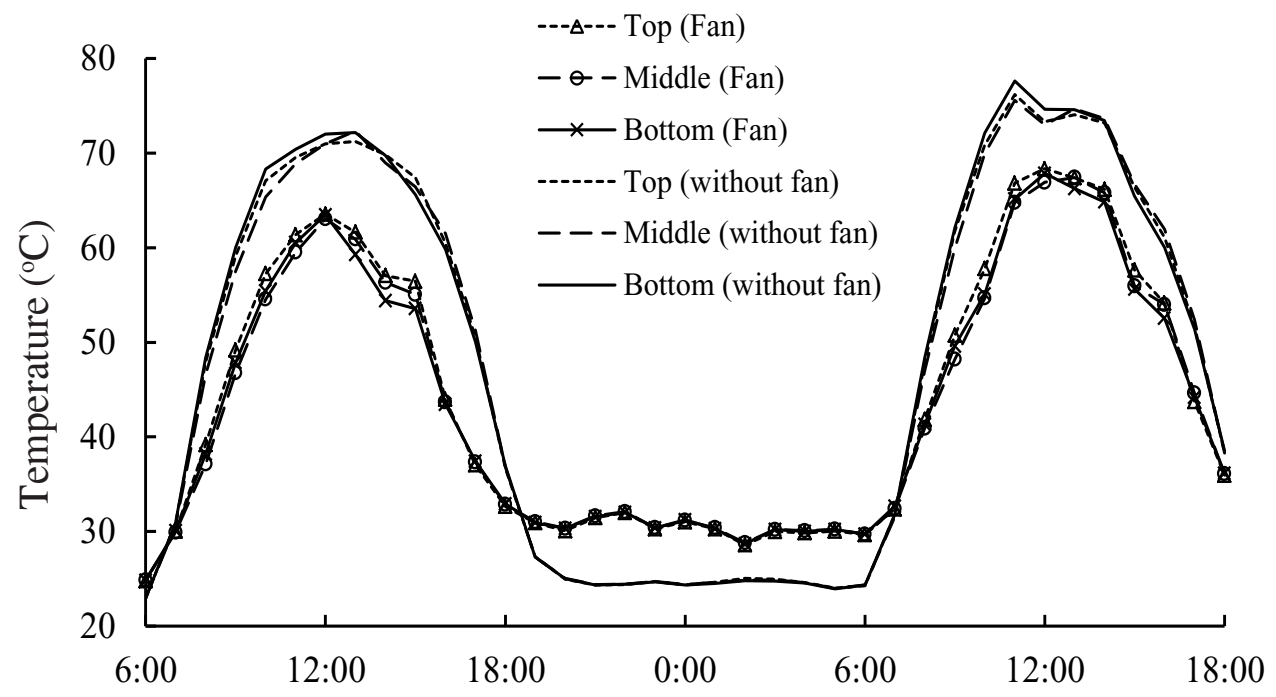

Time (hr)

Figure 9. Variations of temperatures in collector part of the tunnel with and without fan under no-load conditions with time of the day (August 8-11, 2008). 


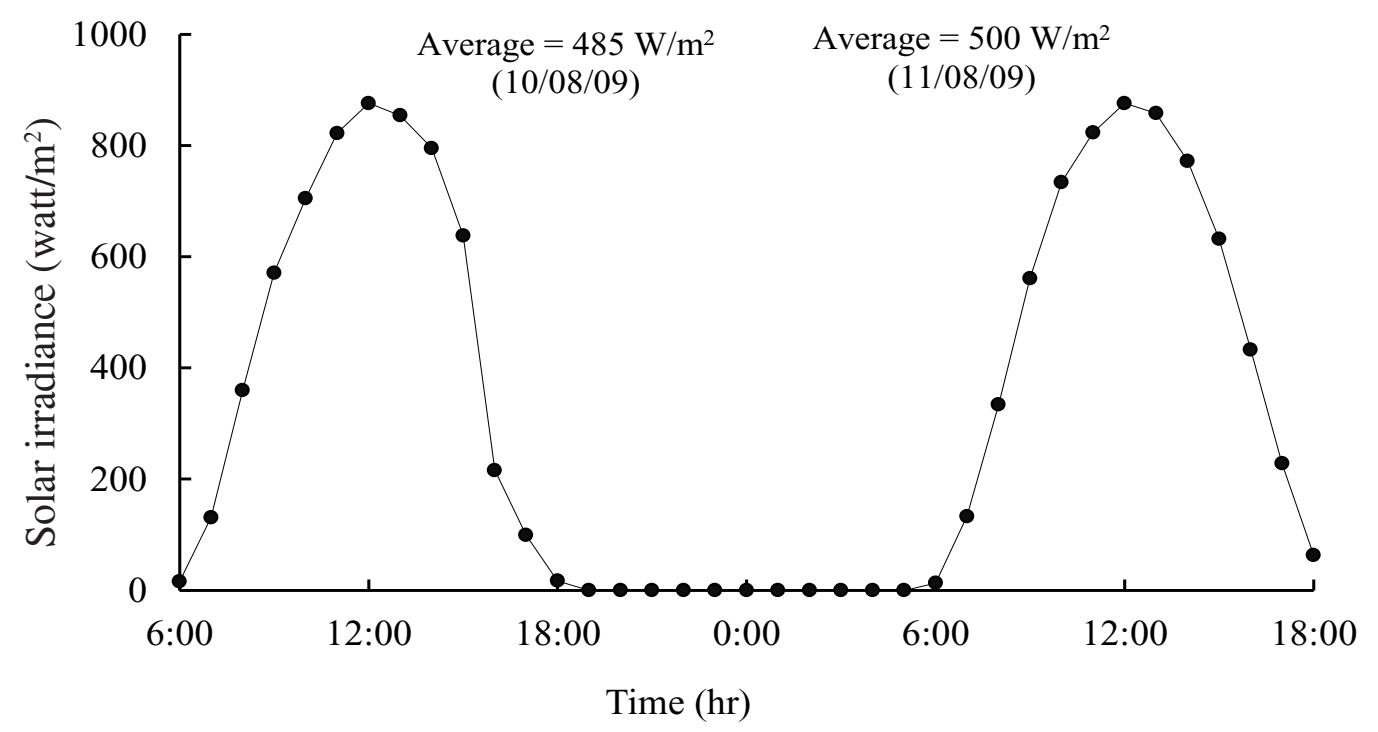

Figure 10. Variations of solar radiation with time of the day (August 8-9, 2008) under no load condition (without product).

\section{Test with Freshly Harvested Dates}

The full test load with $190.2 \mathrm{~kg}$ of freshly harvested dates (khalas variety) was conducted to study the dryer performance on July 27-28, 2009. The average initial moisture content of the freshly harvested dates was $32.8 \%$ (wet-basis). The dates were spread on a wire mesh net in a single layer thickness placed over the plywood bottom of the drying section of the tunnel. The drying was started at 6:30 AM and continued till 6:30 PM. The approximate sun rising and setting time was 6:00 $\mathrm{AM}$ and 7:00 PM, respectively. After termination of the first day drying, the product was kept undisturbed in the dryer and both ends of the tunnel were closed with a polyethylene sheet so that air could not pass through the tunnel. The moisture content was reduced to $21.5 \%$ from an initial $32.8 \%$ wet-basis in 12 hours drying on the first day. The next day drying was started at 6:30 AM and continued till 5:00 PM when the products reached their final moisture content of 18.5 $\%$ (w.b.). Samples were collected for moisture content determination at the end of drying and it was found to be around $18.5 \%$ (wet-basis).

The variations of the dryer and collector air and the ambient air temperatures with drying time (6:00-19:00 hr/ day) in two days are shown in figure 11 . The variations of

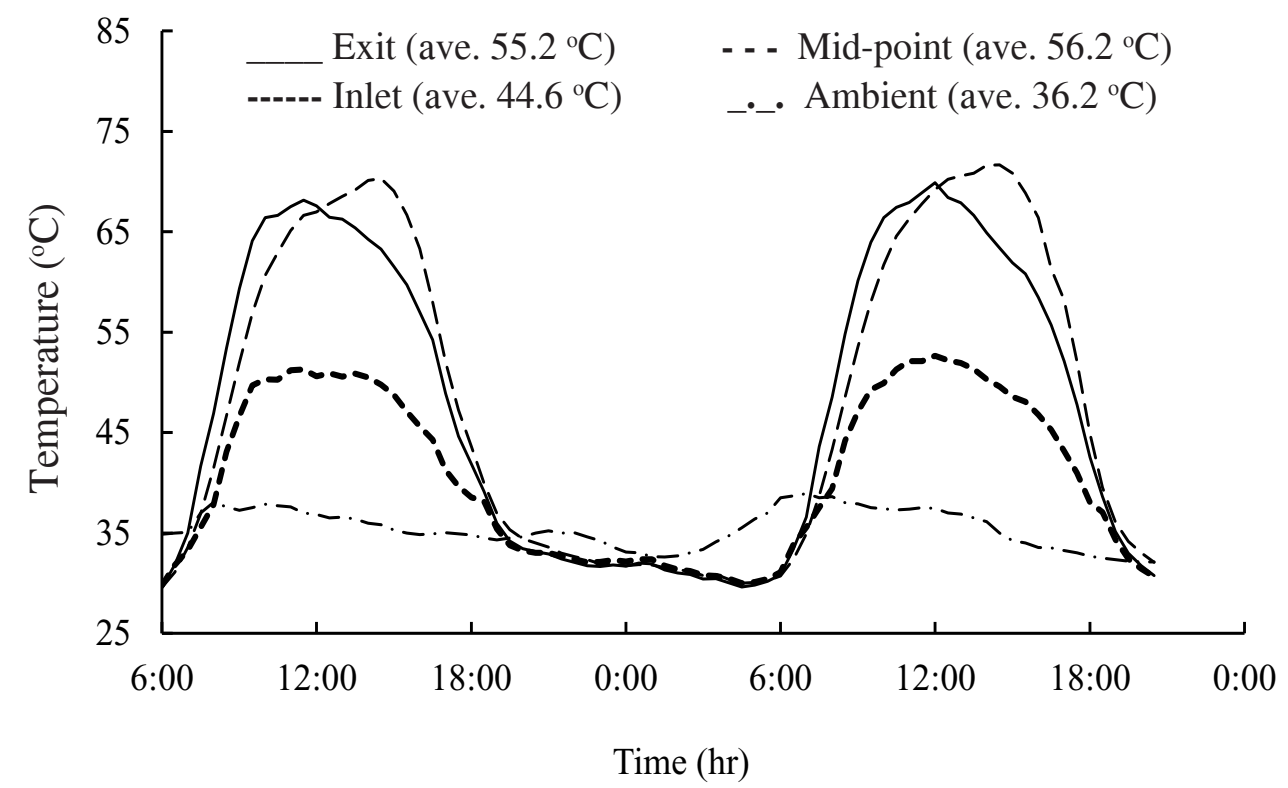

Figure 11. Variations of ambient, dryer and collector temperatures with time of the day (July 27-28, 2009,) in drying freshly harvested dates. 


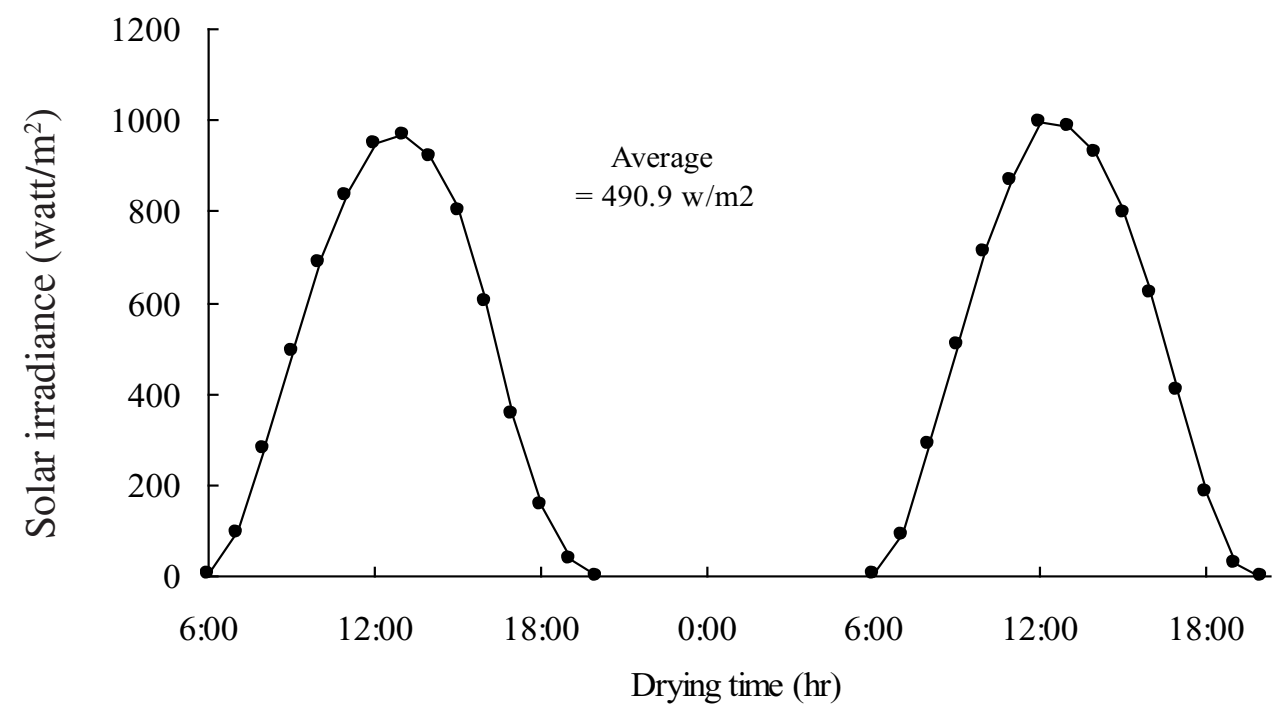

Figure 12. Variations of solar radiation with time of the day (July 27-28, 2009) in drying freshly harvested dates.

solar radiation with drying time are shown figure 12 . The average drying air temperature and ambient temperatures were 52.0 and $36.2^{\circ} \mathrm{C}$, respectively, and the average total radiation on a horizontal surface was $490.9 \mathrm{w} / / \mathrm{m}^{2}$. The average temperature in the collector part was lower than the average temperature in the dryer part because of the fan at the air entrance side of the collector.

To compare the drying rates of the solar tunnel dryer and natural convection open air drying, two separate tests were conducted with about $100 \mathrm{gm}$ samples under the same weather conditions. The samples from the tunnel dryer and open air drying were taken at one hour interval for the first four hours of drying, starting from 6:30 AM and then at two hours intervals till 6:30 PM in order to measure the moisture content against the drying time. The variations of moisture content in the solar tunnel drying and natural open air sun drying with time is shown in figure 13 .

The moisture removal rate was much higher in the solar tunnel dryer than with the open-air natural sun drying (Fig. 13).

\section{Drying Efficiency}

The amount of water removed in two days drying from the product in reducing its moisture content from $32.8 \%$

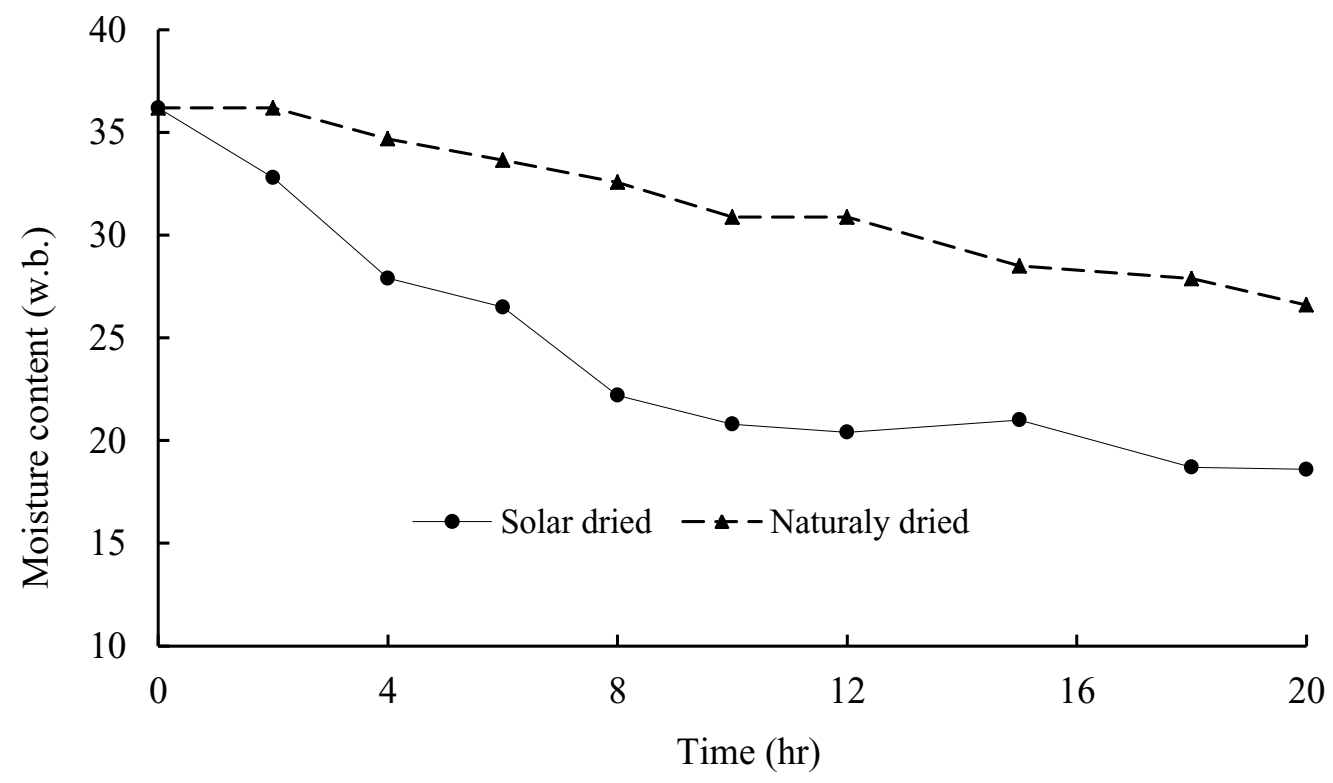

Figure 13. Variations of moisture content with drying time with solar tunnel dryer and natural open air sun drying. 
to $18.6 \%$ wet-basis was $32.8 \mathrm{~kg}$. The latent heat of vaporization of water is $2.5 \mathrm{MJ} / \mathrm{kg}$, and it was considered that the energy requirement in low temperature drying would be very near to the latent heat of water vaporization. The total energy input to the fan in 20 hours was $2.88 \mathrm{MJ}$. The average measured total (beams and diffuses) solar radiation incident on a horizontal surface in two days was $1.77 \mathrm{MJ} /\left(\mathrm{m}^{2} . \mathrm{hr}\right)$. The geometric factor and efficiency of the collector for Muscat, Oman was considered as 1.50 and 35\%, respectively (Duffie and Beckman, 1991; Sodha and Chandra, 1994). The area of the collector was $12.0 \mathrm{~m}^{2}$ and time of the drying was 20 hours. The average drying efficiency of the solar tunnel was found to be $36.4 \%$ in drying dates. The total capacity of the dryer is estimated to be about $200-220 \mathrm{~kg}$ of freshly harvested dates, but 190.2 $\mathrm{kg}$ was loaded. Therefore, the drying area of the dryer was not fully utilized which explains the low efficiency of the drying system. The average collector, dryer and ambient air temperatures in two days drying were 52.6, 51.9 and $36.2^{\circ} \mathrm{C}$, respectively and the averages of relative humidity were $34.0,46.5$ and $55.0 \%$, respectively. It was also observed that the average relative humidity of the air leaving the dryer was fairly low $(37.6 \%)$, while the ambient air relative humidity was $55.0 \%$. This indicated that the potential of the air exiting the dryer was not fully utilized. The relative humidity of the air leaving the dryer could be raised to the relative humidity of the ambient air if the length of the dryer was greater. It is also true that in an overflow drying system, as in a tunnel dryer, it is not possible to fully utilize the harvested energy as the drying air is passed over the product to be dried.

The much softer skin of the dates allows easy diffusion of moisture through it to the drying air at the initial stage of drying. The thickness of the date's muscles also contributed to faster drying, as the average thickness was only about $2 \mathrm{~mm}$. In general, the drying efficiency is reduced considerably during the final stage of drying. This is due to much less mass transfer from the inner part of the dates to the surface after it is dried to a certain extent. This indicates that the diffusion of moisture from inside the product to the surface of the product becomes much more difficult.

\section{Conclusions}

This paper describes the design, construction and experimental investigation of a solar tunnel dryer. The noload tests clearly indicated that the drying temperature can be easily raised to $5-30^{\circ} \mathrm{C}$ above the ambient temperature while the average air flow velocity inside the tunnel was $0.5 \mathrm{~m} / \mathrm{s}$. The average drying air temperature could be easily attained $50-55^{\circ} \mathrm{C}$.

The experiments were carried out with $190.2 \mathrm{~kg}$ freshly harvested dates and the performance of the dryer was compared to open-air natural sun drying. A considerable reduction in drying time in comparison with natural openair sun drying was obtained. The thermal efficiency of the dryer was found to be approximately $36.4 \%$. These investigations show that a solar tunnel dryer can be used for low temperature drying of dates and other agricultural products in the rural areas of Oman where electricity is not available.

\section{Acknowledgement}

The financial support by the IG/AG/SWAE/08/01 for this study at the College of Agricultural and Marine Sciences, Sultan Qaboos University is greatly acknowledged.

\section{References}

Ampratwum, D.B. 2003. Development of solar technology for drying dates. Final Research Report, Sultan Qaboos University, Muscat, Oman.

AOAC. 1984. Official Methods of Analysis (14 ${ }^{\text {th }}$ edition) Association of the Official Analytical Chemists. Washington D.C.

Bala, B.K. and M.R.A.Mondal. 2001. An experimental investigation of solar tunnel dryer. Drying Technology 19:1-10.

Bala, B.K., M.R.A Mondal, B.K. Biswas, B.L. Das Chowdury, and S. Janjai. 2003. Solar drying of pineapple using solar tunnel dryer. Renewable Energy 28:183-190.

Basunia, M.A. and T. Abe. 2001a. Thin-layer solar drying characteristics of rough rice under natural convection. Journal of Food Engineering 47:295-301.

Basunia, M.A. and T. Abe. 2001b. Design and construction of simple three-shelf solar rough rice dryer. Agricultural Mechanization in Asia, Africa and Latin America 32: 54-59, 66.

Duffie, J.A. and W.A. Beckman. 1991. Solar Engineering of Thermal Process. A Wiley-International Publication. John Wiley and Sons, New York.

EI-Sebaii, A.A., S. Aboul-Enein, M.R.I Ramadan, and H.G. El-Gohary. 2002. Empirical correlations for drying kinetics of some fruits and vegetables. Energy 27:845859.

Esper, A., W. Muhlbauer, W. Rakwchian, and S.R. Janjai. 1996. Introduction of solar tunnel dryer for drying tropical fruits in Thailand, Paper presented at the International Seminar on Financing and Commercialization of Solar Energy Activities in South and East Asia, Kunming, China, August 24-31.

Esper, A., O. Hansel, and W. Muhlbauer. 1994. PV-driven solar tunnel dryer. Agricultural Engineering Conference, Bangkok, December 6-9.

Lutz, K., W. Muhlbauer, J. Muller, and G. Reisinger. 1987. Development of Multi purpose solar crop dryer for arid zones. Solar and Wind Technology 4:417-424.

Mastekbayeva, G.A., P.B. Chandika, M.A. Leon, and S. Kumar. 2002. Energy Program,Report. Asian Institute of Technology (AIT), P.O. Box 4, Klong Luang, Pathumthani 12120. 
Mastekbayeva, G.A., M. A. Leon, and S. Kumar. 1998. Performance evaluation of a solar tunnel dryer for chili drying. Paper presented at the ASEAN Seminar and Workshop on Drying Technology, Phitsanulok, June 3-5.

Mercer, D.G. 2008. Solar drying in developing countries possibilities and pitfalls. International Union of Food Science and Technology 4:1-11.
Schirmer, P., S. Janjai, A. Esper, R. Smitabhindu, and W. Muhlbauer. 1996. Experimental investigation of the performance of the solar tunnel dryer for drying bananas. Renewable Energy 7:119-129.

Sodha, M.S. and R.I. Chandra. 1994. Solar drying systems and their testing procedures: a review. Energy Conservation and Management 35:219-267.

Received: January 26. 2010

Accepted: December 16, 2012 
